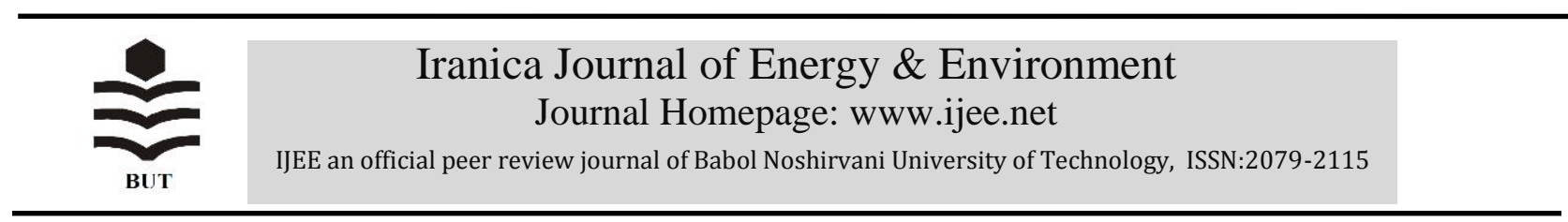

\title{
Energy Productivity Analysis of Industrial Wastewater Treatment Plants: A Data Envelopment Analysis Approach
}

\author{
S. Saghafi ${ }^{*}$, N. Mehrdadi ${ }^{1}$, G. Nabi Bid Hendy ${ }^{1}$ and S. Amani² \\ ${ }^{1}$ Department of Civil \& Environmental Engineering, University of Tehran, Tehran, Iran
}

\section{$P A P E R \quad I N F O$}

\section{Paper history:}

Received 27 November 2018

Accepted in revised form 31 December 2018

\section{Keywords:}

Industrial wastewater

Electrical energy efficiency

Wastewater treatment

Data envelopment analysis

\section{$A \begin{array}{lllllllllll} & S & T & R & A & C & T\end{array}$}

Currently, the efficiency improvement of industrial wastewater treatment plant (IWWTP) has turned into a noticeable challenge for plants operator. In addition, decreasing in the cost and energy consumption of wastewater treatment plants has attracted great interest by water agencies and IWWTP management. Since IWWTPs are energy-intensive facilities, the need for cost-efficient and reliable treatment processes has significantly increased so as to meet the standards of environmental regulations and national goals. Determination of energy efficiency of IWWTPs is a starting point for any energy-saving initiative. In this paper, a case study was carried out in 79 WWTPs in Iran's industrial zones to identify electrical energy efficiency indices (EEI). In order to achieve a reliable result, Data Envelopment Analysis (DEA) was applied by Lingo11 software. The electrical energy efficiency index was estimated by regression equations for plants with different level of treatment (ready to discharge to the river, irrigation of green spaces, and agriculture) using Minitab17 software. The obtained results showed that only $1 \%$ of the treatment plants have high energy efficiency index $(0.8<\mathrm{EEI}<1), 3 \%$ of the treatment plant have high-moderate energy efficiency index $(0.6<\mathrm{EEI}<0.8), 15 \%$ of treatment plants have moderate electrical energy efficiency $(0.4<\mathrm{EEI}<0.6), 22 \%$ of treatment plants have low-moderate electrical energy efficiency $(0.2<\mathrm{EEI}<0.4)$, and $59 \%$ of treatment plants have low electrical energy efficiency $(\mathrm{EEI}<0.2)$. The obtained results enable IWWTP operators to identify the cost items to improve the productivity of plants.

doi: 10.5829/ijee.2018.09.04.03

\section{INTRODUCTION}

Nowadays, there are special attentions for expansion of the productivity of water treatment quality to meet the nation and global environmental standards [1]. The limitation identified with environmental organization and agencies have recently strengthened and confirm national demands and goals [2]. So far, the researchers in the area of wastewater treatment have mostly concentrated on the quality of water and related problems. The significance of water supply with high quality for urban populaces was acknowledged in ancient times. Nonetheless, the significance of appropriate sanitation and wastewater treatment for the security of general wellbeing and nature was not comprehended until the nineteenth century [3]. As we would like to think, endeavors must be completed to connect the quality of water and wastewater treatment plants (WWTP) productivity with the viewpoints of energy saving, since future modern practice with regards to fossil fuel asset rarefaction and the worldwide temperature alteration will be enormously affected the costs of energy [4].

WWTPs are energy consuming plants, and they usually utilize $4 \%$ of the total country's power consumptions for collecting and treatment of water and wastewater.
Nevertheless, energy usage by the different segments of WWTP has expanded impressively as a result of the execution of new advancements to meet new consumable water and gushing treatment quality models. In addition, the cost of energy has expanded considerably at the same period [5]. The unpredictability of energy costs, need to enhance maintenance, energy effectiveness and extend financing made huge chances to enhance energy and operation proficiency at most water and wastewater treatment units. One instrument of building up these open doors is through energy administration arrangements. Focus on wastewater treatment, the dominant part of electrical energy request is required for the conveyance of air to give oxygen to natural treatment of waste streams and blending to suspend solids inside processing units [6]. Air circulation procedures can represent $60 \%$ or a greater amount of the general power utilization at a wastewater treatment plant. With developing climate concerns, energy sparing, expanding energy value, energy productivity and energy substitution have turned into a typical improvement rule everywhere throughout the world [7]. In this unique situation, the utilization of instruments and techniques to spare energy costs has stirred a developing enthusiasm from water 
organizations [8] and WWTP administrators. The evaluation of energy monetary proficiency of WWTPs can be considered as the beginning stage for recognizing potential reserve funds. A standout amongst the most helpful systems is energy effectiveness appraisal utilizing data envelopment analysis (DEA) approach, a non-parametric strategy for performing assessments. Relative investigation empowers recognizing the qualities and shortcoming of each WWTP and spares energy costs [9].

The fundamental promising position of this strategy is its capacity to oblige an assortment of sources of information and yields. Besides, both the information sources and the yields may speak to various units [10]. In any case, the downside of DEA is that the outcomes are conceivably delicate to the determination of sources of information and yields. The use of the non-parametric method has been favored. In this specific context, a few DEA models have been utilized as a part of various settings and for various purposes [11]. All these past reviews, with some exception [12] have surveyed the productivity of the offices utilizing outspread DEA models which empower measuring worldwide effectiveness for each WWTP, i.e. all data in respect to the execution of the office is appeared in a solitary pointer [13]. To demonstrate the productivity of these systems, exact utilizing information from Iran's IWTPs was used. It gives observational confirmation about factors influencing scores of proficiencies. In addition, the composition checks that the DEA models are exceptionally helpful as benchmarking apparatuses and empower distinguishing the qualities and shortcoming at the plant level. In this unique situation, getting a proficiency list for data sources incorporated into the model is extremely helpful for disengaging taken toll things that can speak to conceivable reserve funds thus increment the worldwide productivity of each plant and, along these lines, diminish working expenses [14].

\section{Energy efficiency of wastewater treatment}

In the present financial emergency with unpredictable and rising oil and energy costs, the unfaltering increment of ozone-harming substance outflows, and the predictable exhaustion of non-sustainable power sources, it has turned out to be clear that more practical energy structures and measures are basic to guarantee a supportable economy for what's to come. One of those measures is energy proficiency change. It helps lessening energy necessities regularly with low venture cost. The main worry of the wastewater business has dependably been to meet water quality norms so as to keep open trust [15]. In this manner, WWTPs are normally intended to meet certain emanating prerequisites, without significant energy contemplations. Accordingly, WWTPs are barely at any point outlined because of energy productivity. Their plan and operation is frequently in view of instinct and experience [16], instead of on ideal directions or set focuses. WWTPs are large exceptionally energy concentrated and costly to work. For instance, in the only US WWTPs devour around $2 \%$ of the aggregate sum of power produced [15]. Actually, WWTPs speak to the single biggest cost to nearby governments with up to $33 \%$ of their aggregate spending plan [17], and their energy utilization is relied upon to increment by $30-40 \%$ in the following $20-30$ years [16]. In the light of these actualities, it is shocking that there are not very many articles in the accessible writing dedicated to the energy proficiency streamlining of wastewater treatment forms [4, 18]. So far the wastewater demonstrating specialists have concentrated on displaying the emanating wastewater qualities, while the understood energy angles have gotten next to no consideration. After work, power is the biggest working expense related to wastewater treatment with $25-40 \%$ of the aggregate [19]. In the most widely recognized kind of WWTP, the actuated muck plant, around half of this energy is utilized for air circulation purposes $[16,20]$. It is notable that water and energy are firmly connected. Each progression in the incorporated water cycle-drinking water treatment and supply, wastewater gathering, and cleansing - requires energy, and water is utilized as a part of the era of hydroelectric energy and in the operation of most warm power plants [21]. Since over the most recent quite a few years, energy utilization has extensively developed, both through increments in treated volume and the usage of new advancements gone for accomplishing higher effluent qualities [22]

In any case, we should not overlook that decreasing the WWTP carbon footprint is not only an ecological issue; but, there are likewise imperative financial repercussions [23].

Over the most recent couple of years, we have seen a ceaseless ascent in energy costs, from a normal of $€ 0.0756 / \mathrm{kWh}$ in EU-27 in 2005 to $€ 0.1023 / \mathrm{kWh}$ in 2009 [24]. Along these lines, energy turns into a critical cost calculate squander water treatment, by the large second just to workforce costs [11]. It is intriguing to note that normal energy utilization per cubic meter of wastewater treated does not very much crosswise over nations, regardless of any innovation contrasts by Water Environment Research Foundation in 2010.

The measure of energy required for operations fluctuates broadly among individual WWTPs relying upon emanating attributes, treatment innovation, required gushing quality, and plant estimate [19]. Furthermore, for all WWTP sizes, the vast majority of the energy is expended in natural treatment. In treatment plants, bioreactor air circulation involves in the vicinity of half and 60\% of aggregate WWTP energy utilization. We should likewise remember that energy request in this industry will develop with time because of various components, for example, populace development and the comparing development in the contaminant load to be dealt with additional progressively stringent administrative and ecological insurance gauges for gushing quality and remaining water reuse.

In terms of finance, effectiveness and profitability estimations are a long-standing issue of study. Effectiveness investigation techniques can in like manner be exceptionally helpful for water organizations. In fact, these devices are hardly utilized as a part of this field, particularly in the region of wastewater treatment [18]. A few creators consider the volume of regarded water as a variable when measuring proficiency for water organizations that give drinking water also wastewater treatment administrations. This estimate is not valuable as an estimation of specialized and monetary working proficiency of WWTPs since it doesn't represent toxin disposal yields or cost elements particular to the wastewater treatment handle [25]. An alternate approach, particularly for specialized and financial efficiencies of 
WWTPs, has been utilized by Hernández-Sancho and SalaGarrido [12]. These creators have used the Data Envelopment Analysis (DEA) to get effectiveness scores for wastewater treatment pig cultivates in Taiwan and urban WWTPs in Spain individually. Both papers utilize a spiral DEA model to gauge worldwide proficiency for each WWTP examined [14]. Utilizing a DEA model, an arrangement of scores of vigorous proficiency is registered at plant-level for an example of WWTPs situated in the industrials zones in Iran. As a moment step, we connected a nonparametric test to decide if there are factually noteworthy contrasts in energy proficiency between WWTPs classified as far as their diverse working factors.

\section{MATERIALS AND METHODS}

In this article the analysis is divided into two steps. First, a DEA model is applied to obtain the energy efficiency index (EEI) of each WWTP. In the second step, EEI for WWTP with different effluent quality, including river, irrigation of green spaces, and agriculture were estimated by calculated EEI. Primary data have been collected through field monitoring and corroborated with historical data through discussions with plant operators. Log-book and records of transactions and consumptions are also referred for validation.

\section{Data envelopment analysis}

According to existing technology; the optimal use of all the production factors in a productive process is defined as the efficiency concept. This research applied as a reference to achieve the comparative efficiency by means of analyzed efficient frontier to compare the decision making unit (DMU) behaviors. Production frontier is the results of DMU behaviors while applies minimum inputs to produce an output, or achieves maximum output vector with a minimum input vector. If DMU operates on the efficient frontier or below the efficient frontier, it is considered efficient or ineffective, respectively [26]. DEA methodology is a nonparametric method for the estimation of production frontiers. This method has been established by Cooper et al. [10]. Evaluating the comparative distance from where an individual DMU is located to the estimated frontier can be enabled by DEA methodology. The calculation of the relative distance from the estimated frontier to the location of DMU can be qualified by means of DEA. Hence, the index of the relative inefficiency can be observed as an industry 'best practice' output/input ratio. DAE can be described as a mathematical linear programming technique. For this methodology, there are no requests for the formation of any functional form. Moreover, the setting of weights for each input and output can be conducted without user. DAE permits making an efficient production frontier for measuring the efficiency of all production units. DEA can solve an optimization model which is formulated for each DMU with the detected data/information from input and output; a minimum amount of basic assumption [27]. The different steps involoved to accomplish DEA demonstrated in Figure 1.

In Figure 1, the value of efficiency index for DMUs can be defined as follows:

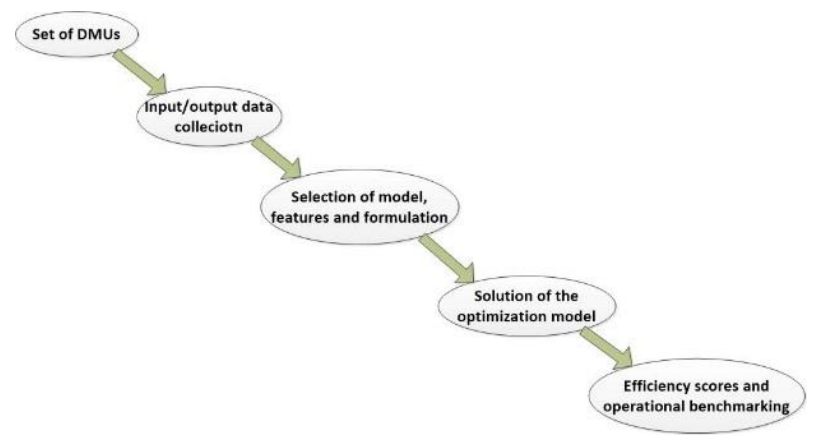

Figure 1. Steps in a DEA methodology [9]

For 1 or efficient units: DMUs which rest on the surface, $<1$ or inefficient units: DMUs which do not establish on the surface. In this context, the electrical energy efficiency of a group of WWTPs was evaluated, using CCR model to obtain a specific indicator of energy efficiency for WWTPs. To determine the efficiency index in the selective treatment plants, the Input oriented CCR model was used. The required codes have been written in Lingo software. Input oriented CCR model is described in Eq. (1).

$\left(\mathrm{DLP}_{0}\right) \min \theta$

s.t. $\theta X_{0}-X \lambda \geq 0$

$\mathrm{Y} \lambda \geq \mathrm{Y}_{0}$

$\lambda \geq 0$

One possible answer for DLP0 can be:

$\theta=0, \lambda_{0}=1, \lambda_{j}=0,(j \neq 0)$

Optimal $\theta$ that is displayed as $\theta^{*}$ is not a value greater than 1 . On the other hand, the second condition implies that $\lambda$ is nonzero due to non-zero data indication. From the third and fourth constraint equation, it can be concluded that $\lambda$ is non-zero. Considering all these facts, it can be concluded that $0<\theta^{*} \leq 1$.

\section{Sample and variables}

For this study, 79 WWTPs located in Iran's industrial zones were assessed as sample. By means of field monitoring which was verified by historical data, the primary data have been composed. Log-book and records of transactions and consumptions were also referred for verification. Moreover, the regular/systematic records of observations are mentioned for verification. All these 79 WWTPs eliminate organic matter and suspended solids by means of an integrated anaerobic/aerobic processes. Some consistency hypothesis about these units can be created by DEA as follows:

A) The units are assumed to be undertaking similar activities and producing comparable products.

B) The relation between the number of DMUs, inputs, and outputs: the number of DMUs has to be at least 2 (number of inputs $\times$ number of outputs), known as 'Cooper rule' [10].

For this study which the source of the wastewater was basically industrial, two outputs have been taken into account: (1) Suspended solids (SS)

(2) Organic matter concentration measured as chemical oxygen demand (COD)

The necessary input to perform the energy consumption of the wastewater treatment plants were energy costs (expressed in Iranian Rials $/ \mathrm{m}^{3}$ ) input data are summarized in Table 1.

(3) The cost of energy: energy consumption (power term) 
TABLE 1. The input and output parameters for measuring the efficiency index

\begin{tabular}{cccc}
\hline Variable & Type & Average value & Units \\
\hline The cost of electrical energy & Input & 22266 & Rails $/ \mathrm{m}^{3}$ \\
COD removal & Output & 89.7 & $\%$ \\
TSS removal & Output & 83.9 & $\%$ \\
\hline
\end{tabular}

\section{RESULTS AND DISCUSSION}

\section{Energy efficiency index in selective WWTPs}

To define energy efficiency index in selective treatment plant, data from 79 industrial wastewater treatment plants were collected. DEA input and output for determination of energy efficiency index are shown in Table 1. Energy efficiency indices in selective treatment plant are also shown in Figure 2 .

As is shown in Figure 2, it can be clearly seen that a large number of treatment plants have a low energy efficiency index. The plants density with energy efficiency index of lower than 0.4 is very high which means that management of electrical energy consumption in the selective treatment is not properly done. Additional energy costs at treatment plants are to be devoted to reduce pollution. In addition, with proper management and enhancement of energy efficiency index in these treatment plants energy consumption would be saved and consequently, energy source would not be easily wasted. However, due to the rising cost of electricity tariffs and targeted subsidies laws in recent years, a lot of saving in treatment plants costs will happen. In Figure 3 percentage of the energy efficiency indicators are shown in different groups of treatment plants.

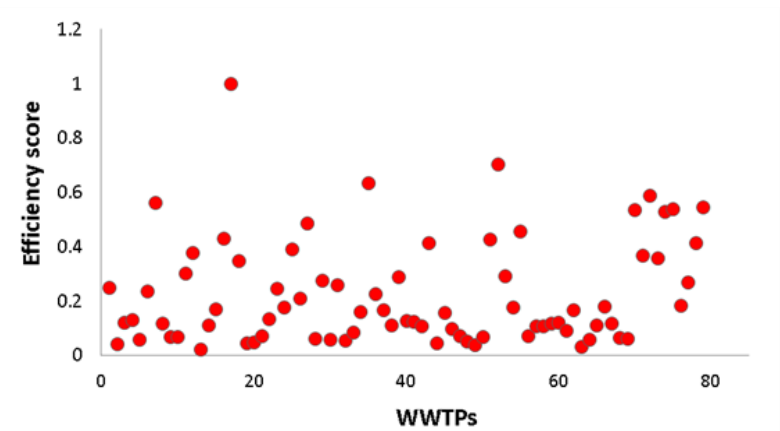

Figure 2. The efficiency index in wastewater treatment plants of industrial zones

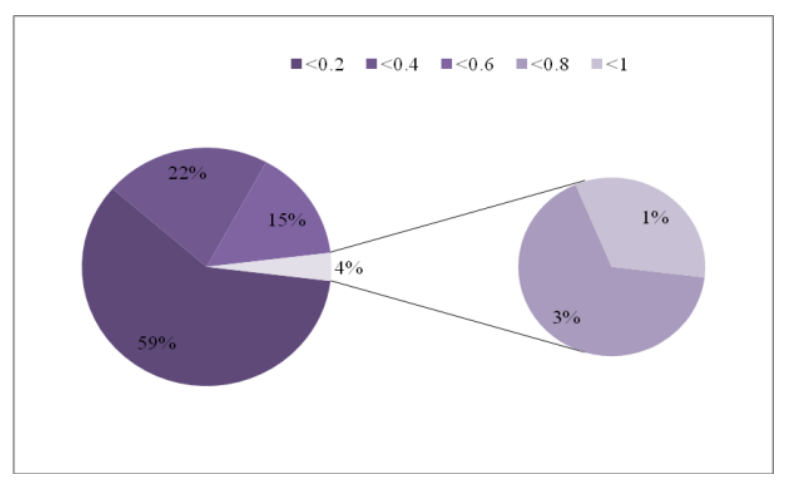

Figure 3. Percentage of the energy efficiency index in WWTPs
As is shown in Figure 3, energy efficiency index in treatment plants is divided into five distinct groups. It can be clearly seen that only $1 \%$ of the treatment plant have high energy efficiency index $(0.8<\mathrm{EEI}<1), 3 \%$ of the treatment plant have high-moderate energy efficiency index $(0.6<\mathrm{EEI}<0.8), 15 \%$ of treatment plants have moderate electrical energy efficiency $(0.4<\mathrm{EEI}<0.6), 22 \%$ of treatment plants have low-moderate electrical energy efficiency $(0.2<\mathrm{EEI}<0.4)$, and $59 \%$ of treatment plants have low electrical energy efficiency $(E E I<0.2)$. This issue is very important in terms of electrical energy consumption; because according to the obtained results about two-thirds of the studied plants suffer from improper management in terms of both wasted energy resources and high energy costs.

\section{Estimating the linear regression equation to determine EEI of IWWTPs}

In order to systematic use of output of Lingo software, electrical energy efficiency index was estimated by statistical software such as Minitab17 and results are indicated in Figures 4 to 6 . The general equation in chosen IWWTPs stated as follows.

$$
Y=C_{1} * X_{1}+C_{2} * X_{2}+C_{3} * X_{3}+b
$$

$\mathrm{Y}$ : EEI in chosen WWTPs

$\mathrm{X} 1$ : COD removal

$\mathrm{X} 2$ : TSS removal

$\mathrm{X} 3$ : The electrical energy consumption in terms of Iranian Rials per cubic meters of raw sewage.

Figure 4 Illustrates the amount of EEIs in WWTPs with a treatment standard adjusted for discharging to rivers. The least amount of EEI in theses WWTPs equal to 0.034 and the highest EEI is equal to 0.591. The EEI equation that was estimated by Minitab17 for IWWTPs which discharge treated effluent to rivers is;

$$
\text { EEI }(\text { River })=0.0000+0.394 \mathrm{X} 1+0.166 \mathrm{X} 2-0.469 \mathrm{X} 3
$$

The above equation is estimated by the amount of acceptable $\mathrm{R}$ and $\mathrm{S}$ that are shown in Table 2.

As shown in Tables 2 and 3, prediction parameters are satisfactory and acceptable. The $\mathrm{R}$ in obtained linear regression model is in a favorable level and the close value of $\mathrm{R}$ with $\mathrm{R}$ - Adjusted showed that there is not additional variable in the model.

Test results of $\mathrm{t}$ test and P-value also confirmed, that the estimated equation is correct. As statistics showed all the coefficients are quite meaningful at $95 \%$ confidence level and the estimated coefficients are consistent with the excising theory. Results also proved that there is no correlation error between the terms.

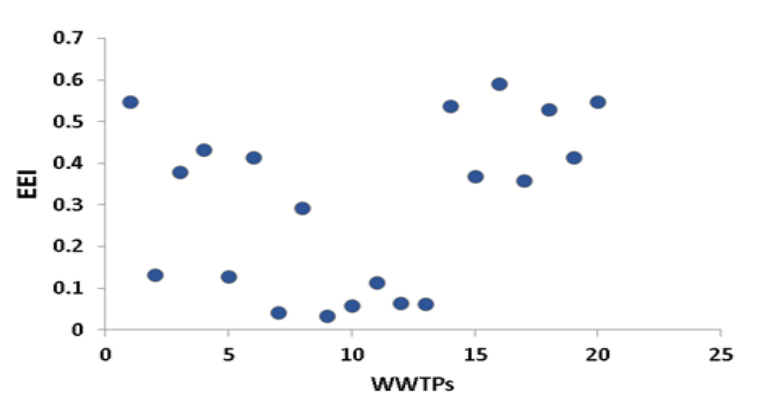

Figure 4. EEI in WWTPs which discharge their effluent to rivers 


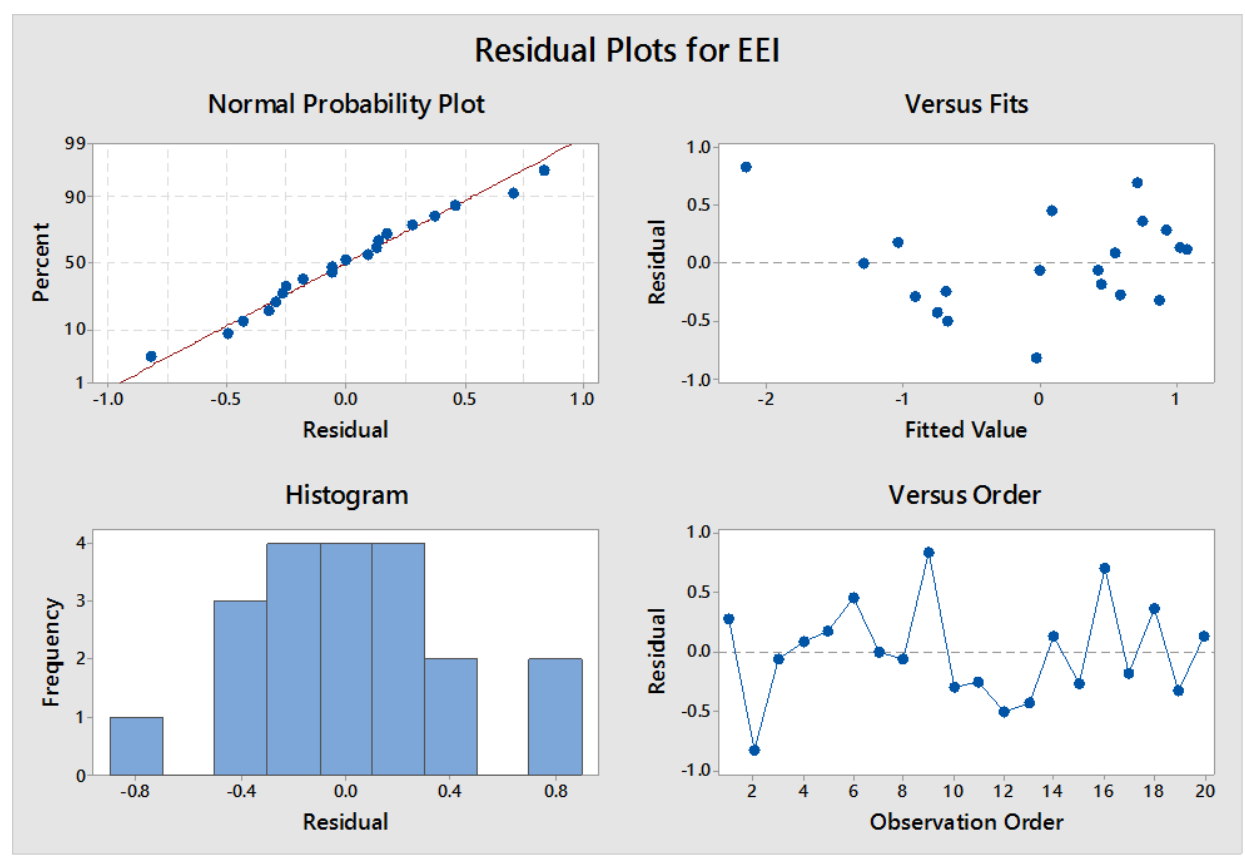

Figure 5. Distributed in the regression model

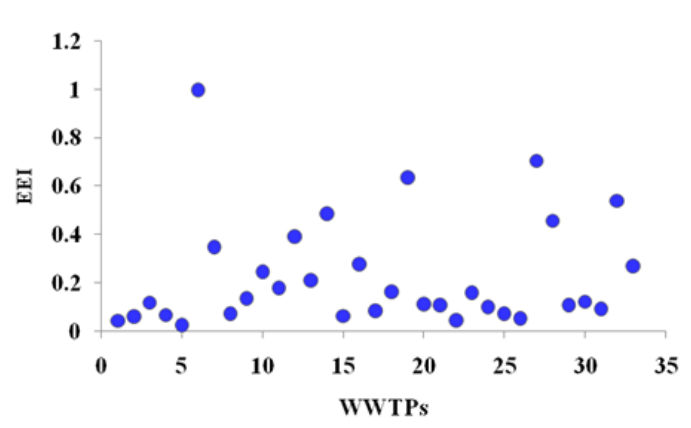

Figure 6. EEI in WWTPs with effluent for irrigation of green spaces

TABLE 2. The $\mathrm{R}$ and $\mathrm{S}$ on the linear regression equation with river usage

\begin{tabular}{ccccc}
\hline S & R-sq & R-sq(adj) & R-sq(pred) & Durbin-watson \\
\hline 0.445 & $\% 83.29$ & $\% 81.16$ & $\% 79.53$ & 2.11 \\
\hline
\end{tabular}

In estimating equation for river model, the highest coefficient is related to electrical energy consumption and is equal to 0.469 . The lowest coefficient is related to COD removal and it is equal to 0.166 . Electrical energy consumption coefficient is negative; which means that lower amount lead to a better results and higher EEI as well

As shown in Tables 2 and 3, prediction parameters are satisfactory and acceptable. The $\mathrm{R}$ in obtained linear regression model is in a favorable level and the close value of $\mathrm{R}$ with $\mathrm{R}$ - Adjusted showed that there is not additional variable in the model.

Test results of $\mathrm{t}$ test and $\mathrm{P}$-value also confirmed, that the estimated equation is correct. As statistics showed all the coefficients are quite meaningful at $95 \%$ confidence level and the estimated coefficients are consistent with the excising theory. Results also proved that there is no correlation error between the terms. In estimating equation for river model, the highest coefficient is related to electrical energy consumption and is equal to -0.469 . The lowest coefficient is related to COD removal and it is equal to 0.166 . Electrical energy consumption coefficient is negative; which means that lower amount lead to a better results and higher EEI as well.

As illustrated in Figure 5, two sets of data are more distributed than the rest of data. This would result in further error in estimating the linear regression equation (shown in different ways in Figure 5). Considering all of the above facts, the proposed linear regression models is acceptable with a low error.

EEI in WWTPs with effluent into irrigation of green spaces is shown in Figure 6. The lowest EEI in WWTPs is equal to 0.063 and the maximum is equal to 1 . EEI equation was estimated by application of Minitab17 software for irrigation of green spaces usage to be as follows, input data is standardized.

EEI irrigation of green spaces $=0.0000+0.16 \mathrm{X} 1$ $+0.451 \mathrm{X} 2-0.317 \mathrm{X} 3$

The above equation is estimated by the amount of acceptable $\mathrm{R}$ and $\mathrm{S}$ that are summarized in Table 4.

As shown in Tables 4 and 5, the predictions model parameters are satisfactory and acceptable, and linear regression model obtained $\mathrm{R}$ in a favorable level. In estimating equation model of irrigation green space usage, the highest coefficient is about TSS removal efficiency with coefficient of 0.451 and the lowest coefficient of COD removal efficiency is equal to 0.16 . Constant factor in the equation is obtained zero. Moreover, $\mathrm{P}$-value is equal to one. It is shown that constant factor is ineffective in a linear regression equation. Test results (T), P-value, Durbin-Watson confirmed that the estimated equation has been correct.

As shown in Figure 7, one set of data is more distributed than the rest of data, this leads a reason to further error in estimating the linear regression equation that is shown in the above fingers. Considering all of these, linear regression models estimated with a low error is acceptable. 
TABLE 3. Predictive parameters in the river model

\begin{tabular}{lcccc}
\hline predictive parameters & coefficient & SE & T & P-value \\
\hline Constant & 0.00 & 0.0096 & 0.000 & 1.000 \\
Removal COD & 0.394 & 0.022 & 1.76 & 0.038 \\
Removal TSS & 0.166 & 0.021 & 0.73 & 0.047 \\
Electrical energy consumption & -0.469 & 0.013 & -3.6 & 0.002 \\
\hline
\end{tabular}

TABLE 4. The $\mathrm{R}$ and $\mathrm{S}$ on the linear regression equation with irrigation of green spaces usage

\begin{tabular}{cccccc}
\hline S & R-sq & R-sq(adj) & R-sq(pred) & Durbin-watson \\
\hline 0.1 & $\% 77$ & $\% 75$ & $\% 71$ & 2.2 \\
\hline
\end{tabular}

TABLE 5. Predictive parameters in the irrigation of green spaces model

\begin{tabular}{lcccc}
\hline Predictive parameters & Coefficient & SE & T & P-value \\
\hline Constant & 0 & 0.0776 & 0 & 1 \\
Removal COD & 0.16 & 0.098 & 0.58 & 0.038 \\
Removal TSS & 0.451 & 0.106 & 1.73 & 0.044 \\
Electrical energy consumption & -0.317 & 0.103 & -2.08 & 0.017 \\
\hline
\end{tabular}

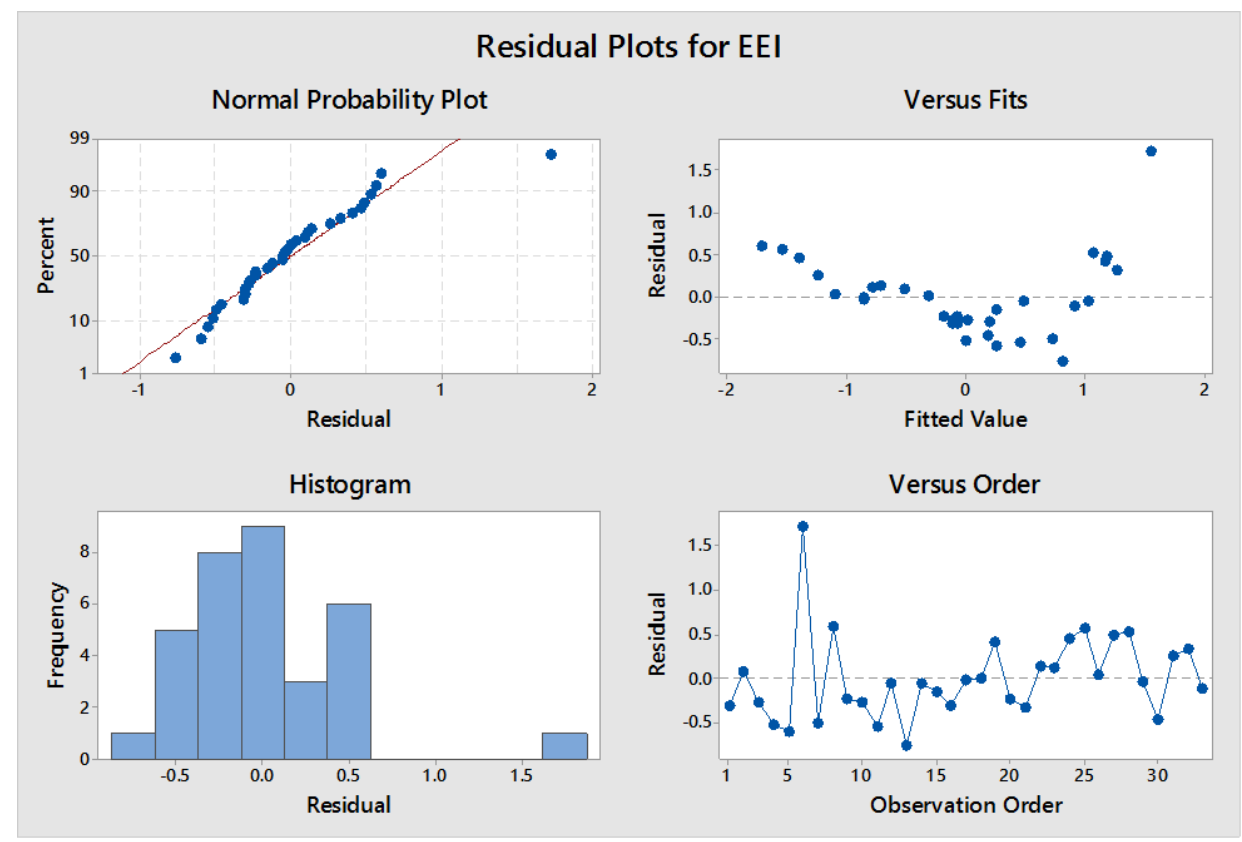

Figure 7. Distribution in the regression model

EEI in WWTPs with effluent into agriculture is shown in Figure 8. The lowest EEI in WWTPs is equal to 0.047 and the maximum is equal to 0.429 . EEI of rest of WWTPs is between these two levels. EEI equation was estimated by application of Minitab17 software for irrigation of green spaces usage to be as follows:

EEI Agriculture $=0.0000+0.560 \mathrm{X} 1+0.091 \mathrm{X} 2-0.335 \mathrm{X} 3$

The above equation is estimated by the acceptable amount of $\mathrm{R}$ and $\mathrm{S}$ that are summarized in Table 6. Input data is standardized.

As shown in Tables 6 and 7, predictions model parameters are satisfactory and acceptable, linear regression model obtained $\mathrm{R}$ in a favorable level. In estimating equation model of agriculture usage, the highest coefficient of COD removal efficiency has a value of 0.56 and the lowest coefficient of TSS removal efficiency is equal to 0.091. Constant factor in the equation is obtained zero also P-value is equal to one. It is shown that constant factor is ineffective in a linear regression equation. Test results (T), P-value, Durbin-Watson confirmed that the estimated equation being correct. Results of estimated three equations indicate factor equation for the electric energy consumption is more important than the other two criteria.

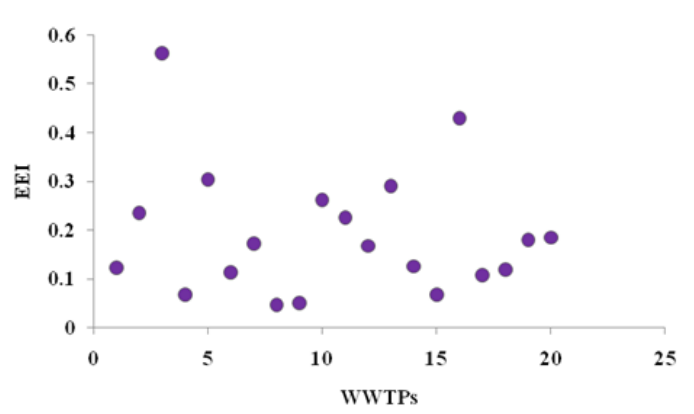

Figure 8. EEI in WWTPs with effluent for agriculture 
TABLE 6. The $\mathrm{R}$ and $\mathrm{S}$ on the linear regression equation with agriculture usage

\begin{tabular}{ccccc}
\hline $\mathbf{S}$ & R-sq & R-sq(adj) & R-sq(pred) & Durbin-watson \\
\hline 0.05 & $\% 83.48$ & $\% 80.38$ & $\% 78.79$ & 1.89 \\
\hline
\end{tabular}

TABLE 7. Predictive parameters in agriculture model

\begin{tabular}{lcccc}
\hline Predictive parameters & Coefficient & SE & T & P-value \\
\hline Constant & 0 & 0.0991 & 0 & 1 \\
Removal COD & 0.56 & 0.101 & 2.23 & 0.011 \\
Removal TSS & 0.091 & 0.112 & 0.35 & 0.043 \\
Electrical energy consumption & -0.335 & 0.129 & -2.24 & 0.029 \\
\hline
\end{tabular}

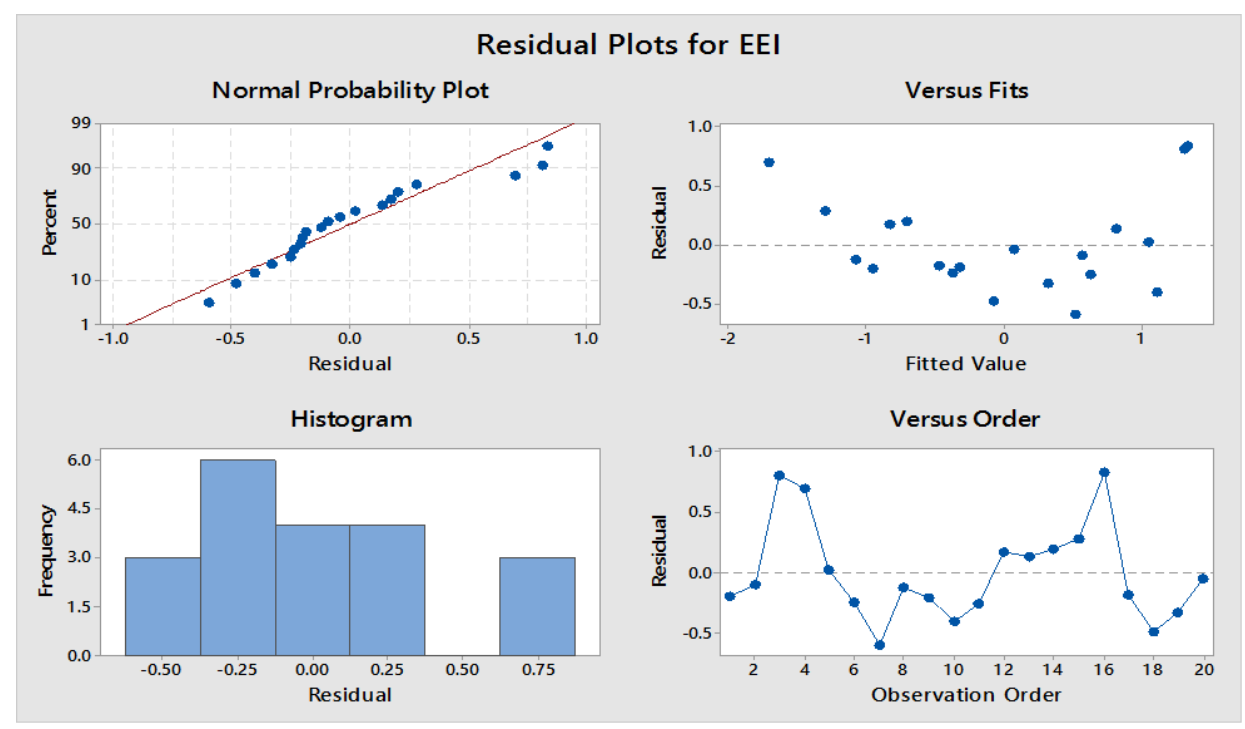

Figure 9. Distribution in the regression model

\section{CONCLUSIONS}

WWTPs are energy-intensive facilities contributing in some measure to usage change. Preferably, this energy utilization is required to become significant because of a higher expected volume of water being dealt with, and also to selection of new innovations gone for yielding higher quality effluents. By dissecting energy proficiency of WWTPs we can recognize which measures have the most elevated capability of lessening energy utilization and thusly ozone harming substance discharges, and enhancing creation costs for such services, making them more aggressive. On account of these destinations, we broke down the proficiency conduct of an example of WWTPs situated in Iran's modern zones, our review affirmed that effectiveness levels for the examined test of WWTPs in all were low and that the quantity of plants working proficiently was little. In this study, we identified which measurements have a high capability in order to decrease energy consumption in industrial wastewater treatment plants. For more accurate studies and the impact of interactions of factors affecting energy consumption and energy efficiency index, 79 IWTPs were selected. Research carried out revealed that energy efficiency level for the selected IWTPs was low and that the quantity of plants working proficiently was little. It has been concluded that only $1 \%$ of the treatment plants have high energy efficiency index $(0.8<$ EEI $<1), 3 \%$ of the treatment plant have highmoderate energy efficiency index $(0.6<\mathrm{EEI}<0.8)$, $15 \%$ of treatment plants have moderate electrical energy efficiency
$(0.4<$ EEI $<0.6), 22 \%$ of treatment plants have low-moderate electrical energy efficiency $(0.2<\mathrm{EEI}<0.4)$, and $59 \%$ of treatment plants have low electrical energy efficiency $(E E I<0.2)$. This problem could reflect a lack of management of electrical energy consumption in the industrial wastewater treatment plants zones. According to the rising cost of electricity tariffs this issue is very important if WWTPs are able to achieve higher energy efficiency index for example a large percentage of them have immediacy Index 1, largely in the electrical energy consumption and cost savings. EEI for WWTPs with effluent for irrigation of green spaces usage and agricultural usage or discharge into the river were considered separately and estimated. In each equations linear regression have good accuracy to estimate the amount of EEI. Results of estimated three equations indicate factor equation for the electric energy consumption is more important than the other two criteria.

\section{ACKNOWLEDGMENTS}

Authors are thankful to Iran Small Industries and Industrial Zones Organization for the partially financial support of present research.

\section{REFERENCES}

1. Macuada, C.J., A.M. Oddershede, and R. Alarcon, 2015. Multi-criteria assessment to automate water treatment plants using the analytical hierarchy process. Journal for Global Business Advancement, 8(2): 236-246.

2. Macuada, C. and A. Oddershede, 2014. Analytic hierarchy process to assess technological system in water treatment plants. International Journal of the Analytic Hierarchy Process, Washington DC, USA, 1-5. 
3. Lofrano, G. and J. Brown, 2010. Wastewater management through the ages: A history of mankind. Science of the Total Environment, 408(22): 5254-5264.

4. Descoins, N., S., Deleris, R., Lestienne, E., Trouvé, and F., Maréchal, 2012. Energy efficiency in waste water treatments plants: Optimization of activated sludge process coupled with anaerobic digestion. Energy, 41(1): 153-164.

5. Bell, K. and S. Abel, 2011. Optimization of WWTP aeration process upgrades for energy efficiency. Water Practice and Technology, 6(2): 2011-2024.

6. Brandt, M., R., Middleton, G., Wheale, and F., Schulting, 2011. Energy efficiency in the water industry, a global research project. Water Practice and Technology, 6(2): 2011-2028.

7. Ebrahimi, A., D.Y. Kebria, and G.D. Najafpour, 2017, Enhancing biodegradation and energy generation via roughened surface graphite electrode in microbial desalination cell. Water Science and Technology, 76(5): 1206-1214

8. Singh, P., C. Carliell-Marquet, and A. Kansal, 2012. Energy pattern analysis of a wastewater treatment plant. Applied Water Science, 2(3): 221-226.

9. Li, D., T., Nanseki, Y., Chomei, and S., Yokota, 2018. Production efficiency and effect of water management on rice yield in Japan: twostage DEA model on 110 paddy fields of a large-scale farm. Paddy and Water Environment, 16(4): 643-654.

10. Molinos-Senante, M., G., Gémar, T., Gómez, R., Caballero, and R., Sala-Garrido, 2016. Eco-efficiency assessment of wastewater treatment plants using a weighted Russell directional distance model. Journal of Cleaner Production, 137: 1066-1075.

11. Cooper, W.W., L.M. Seiford, and K. Tone, 2006. Introduction to data envelopment analysis and its uses: with DEA-solver software and references, Springer Science \& Business Media.

12. Sala-Garrido, R., M. Molinos-Senante, and F. Hernández-Sancho, 2012. How does seasonality affect water reuse possibilities? An efficiency and cost analysis. Resources, Conservation and Recycling, 58: 125-131.

13. Hernández-Sancho, F., M. Molinos-Senante, and R. Sala-Garrido, 2011. Energy efficiency in Spanish wastewater treatment plants: a nonradial DEA approach. Science of the Total Environment, 409(14): 2693-2699.

14. Torregrossa, D., G., Schutz, A., Cornelissen, F., Hernández-Sancho, and J., Hansen, 2016. Energy saving in WWTP: daily benchmarking under uncertainty and data availability limitations. Environmental research, 148: 330-337.

15. Sultan, W.I. and J. Crispim, 2018. Measuring the efficiency of Palestinian public hospitals during 2010-2015: an application of a twostage DEA method. BMC health services research, 18(1): 381-397.

16. Ebrahimi, A. and G.D. Najafpour, 2016, Biological treatment processes: suspended growth vs. attached growth. Iran J Energy Environ, 7(2): 114-23.

16. Rojas, J. and T. Zhelev, 2012. Energy efficiency optimisation of wastewater treatment: Study of ATAD. Computers \& Chemical Engineering, 38: 52-63.
17. Tchobanoglous, G., F.L., Burton, and H.D., Stensel, 2003. Wastewater engineering: treatment and reuse. Boston, US: McGraw-Hill Higher Education.

18. Kalbar, P.P., S. Karmakar, and S.R. Asolekar, 2012. Selection of an appropriate wastewater treatment technology: A scenario-based multiple-attribute decision-making approach. Journal of environmental management, 113: 158-169.

19. Ebrahimi, A., D.Y. Kebria, and G.D. Najafpour, 2018, Improving bioelectricity generation and COD removal of sewage sludge in microbial desalination cell. Environmental technology, 39(9): 11881197.

20. Qiu, Y., J., Li, X., Huang, and H., Shi, 2018. A Feasible Data-Driven Mining System to Optimize Wastewater Treatment Process Design and Operation. Water, 10(10): 1342-1356.

21. Saghafi, S., N., Mehrdadi, G., Nabi Bid Hendy, and H., Amini Rad, 2015. Energy efficiency in wastewater treatment plant emphasizing on COD removal: a case study of Amol Industrial Zone, Iran. Canadian Journal of Pure and Applied Sciences, 9(2): 3441-3448.

22. Guerrini, A., G. Romano, and A. Indipendenza, 2017. Energy efficiency drivers in wastewater treatment plants: a double bootstrap DEA analysis. Sustainability, 9(7): 1126.

23. Marchi, M., V., Niccolucci, R.M., Pulselli, and N., Marchettini, 2018 Environmental policies for GHG emissions reduction and energy transition in the medieval historic centre of Siena (Italy): The role of solar energy. Journal of Cleaner Production, 185: 829-840.

24. Odey, E.A., Z., Li, X. Zhou, and L., Kalakodio, 2017. Fecal sludge management in developing urban centers: a review on the collection, treatment, and composting. Environmental Science and Pollution Research, 24(30): 23441-23452.

25. Ebrahimi, A., D.Y. Kebria, and G.D. Najafpour, 2018, Co-treatment of septage and municipal wastewater in a quadripartite microbial desalination cell. Chemical Engineering Journal, 354: 1092-1099.

26. Ebrahimi, A., G.D. Najafpour, and D.Y. Kebria, 2018, Performance of microbial desalination cell for salt removal and energy generation using different catholyte solutions. Desalination, 432: 1-9.

27. Kollmann, R., G., Neugebauer, F., Kretschmer, B., Truger, H., Kindermann, G., Stoeglehner, T., Ertl, and M., Narodoslawsky, 2017. Renewable energy from wastewater-Practical aspects of integrating a wastewater treatment plant into local energy supply concepts. Journal of cleaner production, 155: 119-129.

28. García-Cebrián, L.I., F., Zambom-Ferraresi, and F., Lera-López, 2018 Efficiency in European football teams using WindowDEA: analysis and evolution. International Journal of Productivity and Performance Management, 67(9): 2126-2148.

29. Castellet, L. and M. Molinos-Senante, 2016. Efficiency assessment of wastewater treatment plants: A data envelopment analysis approach integrating technical, economic, and environmental issues. Journal of environmental management, 167: 160-166.

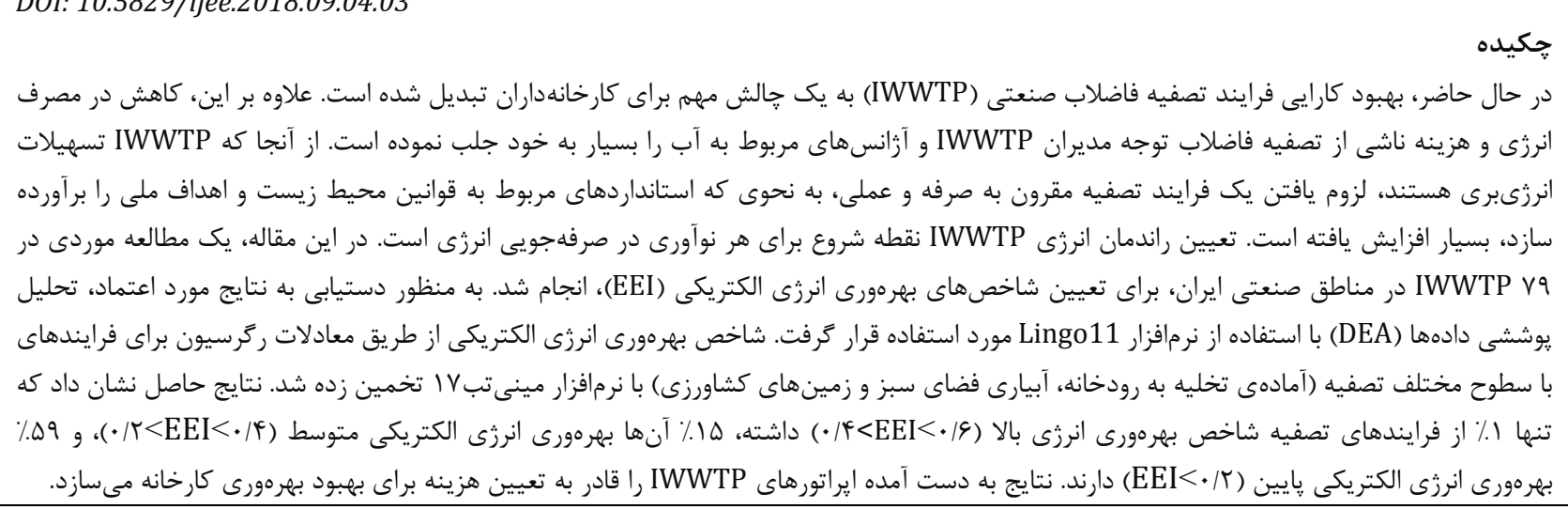

